\title{
A new framework for embedding sustainability into the business school curriculum \\ Petra Molthan-Hill
}

In this chapter some of the key concepts used in this book and in sustainable management are briefly introduced. Students might find it useful if they want to understand some of the underlying concepts or deepen their knowledge. However, this chapter is mainly written for lecturers and other staff members as guidance and a framework on how to embed sustainability into management/business education. Anyone tasked with embedding sustainability into the curriculum of a business school will find ideas about the various approaches they can take and how it can be all combined together. The following questions will be addressed:

- What structural approaches can be been taken by business schools to embed sustainability into the curriculum? (More a question of how it is taught rather than what is taught.)

- What should be taught/studied? What have been identified as core skills and knowledge in sustainable management? 
To facilitate this decision-making, a new conceptual framework for embedding sustainability into the business and management curriculum will be suggested. This framework can be used to assess the current status of how well sustainability is embedded in a business school and how it could be developed further.

The first question to be addressed is how sustainability can be embedded in the structure of a business school. Godemann et al. (2011) developed a matrix to distinguish between the different approaches adopted by business schools (see Fig. 1).

In the first quadrant, the 'piggyback' approach, the business school will add some sustainability-related material to an existing module, such as a case study with a sustainable focus, a framework used in sustainable management such as the life-cycle assessment (see Chapter 9), or some suggestions for further reading. The material in this book can be used for such a 'piggyback' approach, as lecturers/business schools can choose to add one or more of the suggested seminars to an existing module. A student reading this book might also choose this approach and read a chapter on sustainable marketing in addition to what has been covered in a marketing module, for example. The 'piggyback' approach is a good starting point as it does not require much effort to integrate sustainability in this way. However, in the long term it would be better to embed sustainability throughout each module, so that related concepts can be integrated where they belong in the 'core teaching'. For this purpose the following chapters of this book offer additional teaching material and further reading.

The next approach, 'digging deep', is also an easy way to implement sustainability, as it is normally easier to offer a new elective/option than to change the existing curriculum. The content in this book can be used in this way, so that business schools can offer a 'Sustainable Management' option in addition to their existing portfolio. In such a case all 36 seminars in this book can be offered in a year-long module. Or business schools could choose to offer, for example, a module on 'Greenhouse Gas Management' using the material in Chapter 12, so that some students are 'digging deep' in this area and developing a special expertise that will 
Figure 1: Matrix to illustrate integration of sustainability.

\begin{tabular}{lll}
\hline & Existing structures & New structures \\
\hline $\begin{array}{l}\text { Narrow } \\
\text { curricular }\end{array}$ & Quadrant 1 & Quadrant II \\
& Piggyback & Digging deep \\
& Integration of sustainability within & Integration of sustainability through \\
& existing structures by adding & new stand-alone modules \\
& sustainability to individual sessions & \\
& of courses or modules & \\
\hline Broad & Quadrant III & Quadrant IV \\
curricular & Mainstreaming & Focusing \\
& Integration of sustainability within & Integration of sustainability though \\
& existing structures but with the & new cross-disciplinary offerings \\
& emphasis on a broader cross- & such as sustainability-related \\
& curricular perspective (entire & courses which are required for all \\
& curriculum) & business school students and new \\
& & programmes \\
\hline
\end{tabular}

Source: Adapted from Godemann et al. (2011), based on Rusinko (2010).

help them in the jobs market, given that graduates with this expertise are so sought after (Lacy et al. 2010). Even though this approach has its benefits, students may still not choose this option and therefore will not develop sustainability literacy, a skill set each student should acquire as shown below.

The preferred approach for the application of this book is the third approach, 'Mainstreaming'. Each core subject would add the appropriate sections of this book to its teaching, so the seminars on sustainable marketing would be integrated into the marketing module, the one on environmental economics into the economics module, and so on. Initially they could just be added at the end of the first year for example, but it is recommended that this should be developed further and that sustainability should be fully integrated into the core curriculum in every part where it belongs. It is important that this mainstreaming approach should be co-ordinated to some extent. For example, it would not be good for the 'triple bottom line' to be introduced several times, once in accounting, once in human resources and so on. It might be beneficial, therefore, to have some general introductions to sustainability (our Chapters 3, 4 and 14) at the beginning of the first year and then build on 
these in the following core modules. Some aspects of the sustainability literacy approach (Stibbe 2009) could be included in this general introduction: more on this later.

The fourth quadrant, 'Focusing', also addresses the broad curriculum, but requires new structures to be established. An example could be an online course offered to students from all disciplines, introducing them to the main principles of sustainability as applied to different disciplines such as law, business, science or psychology. At Nottingham Trent University we offered such a 'Sustainability in Practice' certificate in the 2013/14 academic year, with the focus on sustainability and food. In the online sessions students could access this topic via their own discipline, but they could also learn how 90 other disciplines would approach the same topic of food and sustainability, from astrophysics to equine studies to psychology. One of the benefits of such an approach is that students realise how their own discipline relates to all the others, and that common sustainability challenges can be only solved when disciplines work together. This specific certificate is optional, and is therefore more linked to the 'Digging deep' approach, but it could be made obligatory and would then be an illustration of a 'Focusing' approach.

Goworek and Molthan-Hill (2013) have demonstrated how these different dimensions can be integrated in a business school, and have given many practical examples for each of the different approaches described above.

\section{A new framework for embedding sustainability into the business school curriculum}

Although the Godemann et al. (2011) matrix is helpful for making decisions on how sustainability can be integrated into the curriculum, it is less so on what should be taught. Sustainability-related teaching content needs to differentiate further between general sustainability knowledge (such as climate change), specific sustainability action strategies in business (subject-specific knowledge), and sustainability literacy skills, which are transferable and competency based. 


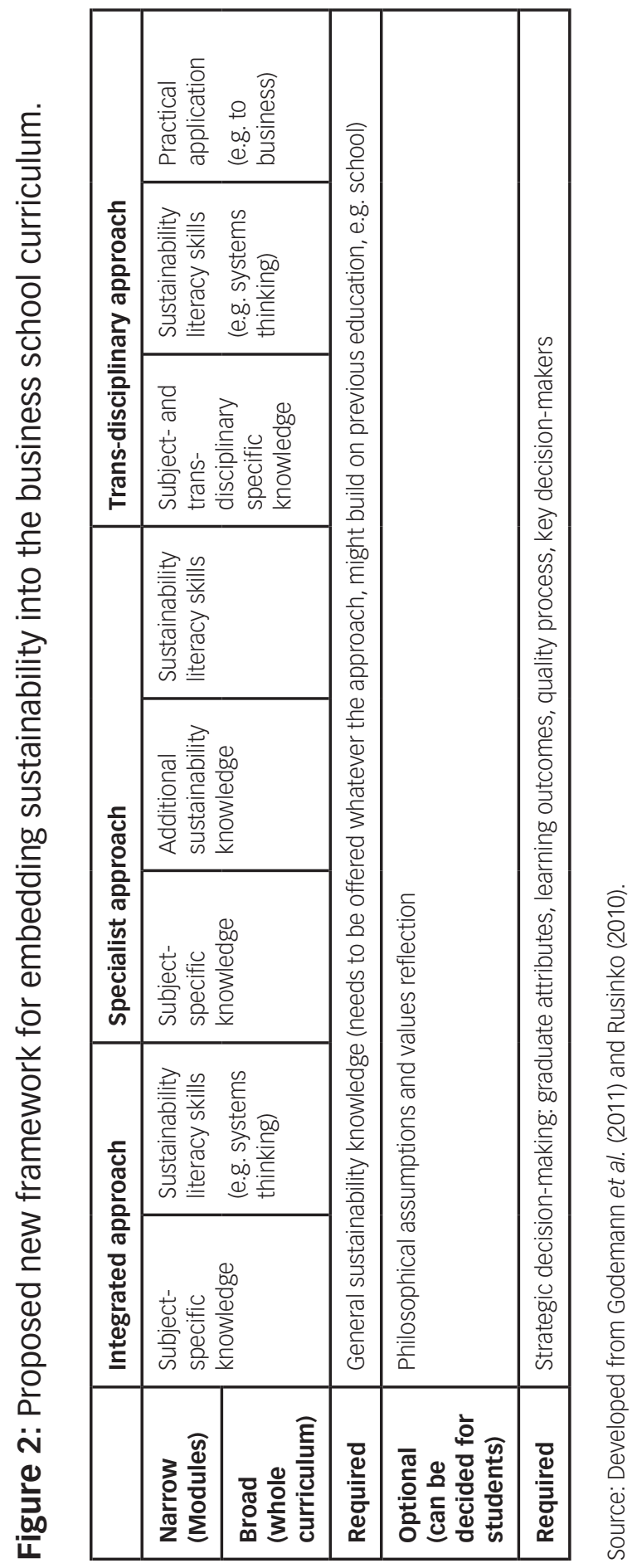


These different categories have therefore been integrated into a new framework, shown in Figure 2, suggesting how to embed different aspects of sustainability into the curriculum, how it could be taught and what could/should be taught. These new dimensions are explained further in the remaining parts of this chapter.

\section{Sustainability-related knowledge}

In the past, teachers and lecturers taught and tested lexical knowledge of sustainability-related topics such as which animals are threatened by extinction or which pesticides are harmful. According to Bodenstein et al.'s (1997) study about the relationship between environmental knowledge and consumer decisions, a good lexical environmental knowledge merely indicates a consumer's educational background (particularly in science subjects) and their newspaper reading habits, and does not give any indication of whether they will engage in activities to improve environmental or social problems. Instead they insisted that students/consumers need to have action-specific knowledge. In their study involving German consumers, their lexical environmental knowledge and their engagement, they were able to highlight that $80 \%$ could answer questions related to lexical environmental knowledge, but only $30 \%$ could name at least one ecological brand or company, even though $71 \%$ claimed that they cared a lot about the environmental friendliness of products.

Another study about climate change also illustrates clearly how important specific knowledge about appropriate alternative actions appears to be needed for environmentally friendly behaviour. Kempton et al. (1996) analysed the environmental perception of five different American subgroups back in 1996. At that point in time the interviewees were linking global warming to ozone depletion; they claimed that energy efficiency and reduced energy consumption had no impact on the greenhouse effect. This study also suggested that action-oriented knowledge depended on specific knowledge of the causes of a particular environmental problem. Translated into our topic, for example, business students would need to have a basic understanding of climate change. They would also need to know what causes climate change and how to apply this to a business context. Furthermore they would then need to know which action 
strategies they can employ as future managers and employees to address these issues. We have followed this three-step approach in Chapter 12: the students learn first about the science of climate change and what causes climate change; in the next step they link it to the impact business has on climate change; and finally they are taught action strategies for how to reduce a company's greenhouse gas emissions.

The focus of the other chapters of this book is to teach these action strategies in business, so students will learn tools and techniques for how to integrate sustainability into marketing, for example. We call this subject-specific knowledge. If readers are interested in increasing their general (lexical) understanding of sustainability-related topics such as the sustainability of food, a very good starting point is Robertson's (2014) Sustainability Principles and Practice, although here less attention has been given to action strategies, which readers need to find or develop through other resources.

Subject-specific knowledge can be taught in various ways as suggested in Godemann et al.'s (2011) matrix: do students learn about sustainability accounting, for example, in an option or in a core module? If in the core module, will it come at the end or will it be integrated throughout the module right from the beginning?

In addition, students need to understand topics such as GHG (greenhouse gas management) in a company. As Chapter 12 shows, GHG management covers corporate strategy, operations, accounting and marketing, so it cuts across different subject areas. Students need to have a basic understanding of how this applies to their subject, or to the profession they will choose for their career.

However, using the analogy of IT, everybody in today's society needs to know the basics, but we also need specialists. This applies even more to sustainability. Everyone needs to understand the basics, but some need to have specialist knowledge. Therefore a business school should teach the basics of GHG, for example, to each student, but also offer some the chance to become specialists by offering a year-long module on GHG management. In our chapter about GHG management we have made different suggestions for lecturers/business schools who want to introduce GHG management as a specialised stand-alone module. 


\section{Sustainable literacy}

Several authors (Stibbe 2009; Courtice and Van der Kamp 2013) have indicated that subject-specific knowledge alone will not be sufficient to develop managers who can deal with sustainability challenges appropriately. In the first Handbook of Sustainability Literacy, Stibbe (2009: 10f) illustrated the different aspects of sustainability literacy and defined the term as follows:

This book uses the term Sustainability Literacy to indicate the skills, attitudes, competencies, dispositions and values that are necessary for surviving and thriving in the declining conditions of the world in ways which slow down that decline as far as possible. Gaining practical skills requires a form of learning which goes beyond memorising and repeating facts. It requires active learning, a broad term used to refer to self-reflection, selfdirected enquiry, learning by doing, engagement with real life issues, and learning within communities of practice.

Several aspects of sustainability literacy have been included in this book, such as materials awareness: the ability to expose the hidden impacts of materials on sustainability (Watson 2009), commons thinking (Kenrick 2009) and ecological intelligence (Sterling 2009). In this introduction we will reflect on three key sustainability literacy skills as applied to management and business: systems thinking, values reflection and philosophical assumptions in business. Other skills have been integrated in individual chapters without making them explicit; a whole list of these skills can be found in Stibbe's (2009) handbook. Furthermore, Robinson (2009: 131f) pointed out:

It is essential that learners are introduced to 'real world' examples and case studies. This could involve, for example, engagement with local organisations and employers or their own institutions by conducting informal environmental audits for them, or researching the activities of larger organisations to expose environmentally damaging practices and to identify paths for improvements. 
Our experience has also been that students benefit from solving problems in the 'real world' and society benefits from it too-throughout the book you will find different projects as undertaken by our students, normally in the 'additional teaching material' section. If you are interested in developing something similar, you can find more information in the teaching aid mentioned on page 4; in some cases, direct contact details are provided in the chapter itself, such as for the strategic management project in Chapter 11.

\section{Systems thinking}

Systems thinking is seen as a fundamental concept in sustainability (Robertson 2014; Stibbe 2009; Clayton and Radcliffe 1996), and a system is often defined as a 'coherently organised set of elements' (Meadows 2008: 188). Robertson (2014: 4) defines it further:

A property of every system is that its identity is always more than the sum of its parts. The Earth itself is a system, made of many other nested and interrelated systems; the biophysical world is an intricate and multi-layered web, a complex, three-dimensional network of interconnected systems.

Schoemaker (2008) criticises business schools/lecturers for opting to teach well-defined problems and frameworks without offering support in how to deal with the 'messy ambiguities of the real world'. Systems thinking encourages acceptance of the complexity of the world and suggests ways of dealing with the massive amounts of information and interconnectedness. As it is such an important concept in sustainable management, it is not only embedded in many of the chapters through this book, but also further explored in its own right in Chapter 14.

Worth mentioning here as a way of integrating systems thinking into the curriculum is to offer a computer simulation game such as Meadow's (2001) Fish Banks Ltd. During this three-hour game, students are asked to run fishing companies with the aim of maximising profit for their shareholders. In addition to the original game we have added some features, such as 'press announcements' from Greenpeace highlighting fish decline 
and recommendations for fishing quotas from the European Union. We have also added interaction between the 'companies' (i.e. groups of students), such as a meeting of the 'trade organisation', in which they have to discuss the possibility of a quota. In all games we have played so far at Nottingham Business School, and previously at Manchester Business School, students were so focused on their profit that first they overfished the 'deep sea' (where the profit is higher) before then turning to the coastal area to overfish there. Sometimes there is one company which attempts to act in a more sustainable manner, but they have never been able to persuade their colleagues to do likewise. If students decide to agree on a quota at all, they normally do so too late in the game when fish stocks have already declined beyond repair. Normally, at this point in the game, the company which has had the highest profit and the biggest shipping fleet will block any agreement. The collapse of the whole fishing industry appears to be something of a revelation for students, as is the calculation of the reasonable amount of money the companies could potentially have made while still maintaining their industry by fishing at a sustainable level, as revealed in the debrief. At this point, concepts such as 'systems thinking' and 'sustainable management' are also explained in relation to the game.

\section{Values reflection}

Another skill students need to develop in business education is to reflect on their values or to even realise that values feature in all business-related models. Several authors (MacIntyre 1981; Watson 2003; Verhezen 2010; Trapp 2011) highlight the fact that managers are reluctant to talk about the moral dimensions of their work, or might insist that they try to be objective when it comes to business decisions, separating business interest from their own or other people's values.

Bird and Waters (1989: 73) label this phenomenon the 'moral muteness of managers':

Many managers exhibit a reluctance to describe their actions in moral terms even when they are acting for moral reasons. They talk as if their actions were guided exclusively by organizational interests, practicality, and economic good sense even when in practice they honour 
morally defined standards codified in law, professional conventions, and social mores. They characteristically defend morally defined objectives such as service to customers, effective co-operation among personnel, and utilization of their own skills and resources in terms of the long-run economic objectives of their organizations.

Molthan-Hill (2014a) proposes that there is no value-neutral way of doing business, rather it is a conflict between established values, which are framed as objective, and new or different values such as environmental protection, which are framed as ethics. Jones (1991: 380) points out that managers/business students need to be able to identify the moral aspects of any business decision they have to make: 'a person who fails to recognise a moral issue will fail to employ moral decision-making schemata and will make the decision according to other schemata, economic rationality, for example'.

This is especially true when it comes to considering environmental or social values in a business decision: here, often a bureaucratic, resourceorientated approach will be chosen. As Crane and Matten (2010) point out, all stages, not only the first one in the ethical decision-making process, are influenced by the issue's moral framing; the most important aspect of moral framing being the language in which moral issues are presented. The problem, they observe, is 'that many people in business are reluctant to ascribe moral terms to their work, even if acting for moral reasons, or if their actions have obvious moral consequences' (p. 153). Therefore, business students need to be enabled to identify the moral dimensions of normal business activities and decisions. In our experience, students tend to highlight business problems, but have difficulty defining the underlying values or even acknowledging them. Furthermore, we often get the impression that students do not feel so comfortable talking about ethical issues. This was also observed by Bird and Waters (1989: 78) in relation to managers, suggesting that the latter need to learn how to express themselves in moral terms:

Managers also shun moral talk in order to not expose their own ethical illiteracy. Most managers neither know nor feel comfortable with the language and logic of moral philosophy. At best they received instruction in juvenile 
versions of ethics as children and young adults in schools and religious associations. They have little or no experience using ethical concepts to analyse issues. They may more readily and less self-consciously use some ethical terms to identify and condemn obvious wrongdoings, but do not know how to use ethical terms and theories with intellectual rigor and sophistication to identify and resolve moral issues.

Therefore, students need to learn mature moral language as part of their sustainability skills set, in order to participate in the moral business discourse. They need to learn the appropriate words and concepts, but they also need to learn how to apply these concepts in the business world. Finally, the 'moral neutrality' of the business world needs to be questioned in the classroom (and maybe not only there ...). A discussion about the morality of ends and the morality of means within the business world needs to become the centrepiece of any sustainability study, so that students reflect on their own values and decide for themselves which of them they consider applicable to the business world. Any module could start with a reflection on the values to be integrated into this subject area: for example, for accounting this could mean that the first session would discuss what needs to be included in a report to give a 'true' picture of the company. Should we focus only on financial values? Why? Should we give a financial value for environmental impacts and, if yes, how and also how much? In this sense every subject would start with a philosophical discussion as also outlined in the next section. In this book, ethics is integrated into each chapter, but often not explicitly. Sometimes students will be asked to express their own values as, for example, in Chapter 3.

\section{Philosophical assumptions in business}

Values reflection is part of understanding philosophical assumptions. Often lecturers and students are not aware that the different business concepts and tools being taught have different underlying philosophical assumptions. In order to include sustainability, we can either involve students in the philosophical discussion of what should form part of a sustainably designed business system, or lecturers can decide what the 
philosophical assumptions are, and whether to make it make it explicit to students or not-as in the current system.

In his article 'Behind Global System Collapse: The Life-Blind Structure of Economic Rationality', McMurtry (2012) complains that 'social life standards to rationally regulate choices to cohere with life support systems are blinkered out' of the common understanding of 'economic rationality' (p. 50). In his opinion, this so-called “"rationality” rules out everything required for a healthy and flourishing human life' (p. 52). He recommends instead a 'life-coherent rationality' which is judged by 'consistency with and satisfaction of organic, ecological and social life requirements' (p. 56).

Our proposed new framework on how to embed sustainability into a business school curriculum suggests an optional module in business philosophy (see Fig. 2). Here students might discuss the underlying philosophical assumptions of an existing business system. I remember vividly how, in my first year of studying business as an undergraduate in Germany, the lecturer asked us to compare one of our (Western) economics books with one published in the GDR (German Democratic Republic) that introduced a planned economy. It became obvious that even the concept of 'demand' (and supply) could be phrased very differently, depending on the underlying philosophical assumptions!

The aim of such a module could not only be the analysis of existing frameworks and concepts, but also to design new concepts and tools while 'structuring what is to be preserved' (Habermas 1984: 398). With regard to environmental issues, it would also allow room for discussions on how environmental and social issues could become part of such new concepts and tools.

For example, economic sustainability has been commonly defined as securing the profitability of a company in the long term (Crane and Matten 2010). However, according to Molthan-Hill (2014b: np):

it might be better to define it similar to the German understanding of survival, so that the company has to survive financially even when they integrate social and environmental issues into their strategic decision-making. Or to search for a different concept of 'economic rationality' combining the German and British approach as a starting point. 
The three dimensions of sustainability-social, environmental and economic-could be assessed, and tools could be created showing how to balance them in our business system. This is the approach taken in some of our chapters. This discussion about philosophical assumptions could be also the starting point in any discipline for reflection on the existing tools in business-for example in marketing or operations-in order to improve or redesign them.

Philosophical questions are only discussed in some chapters of this book. If business schools/lecturers/students want to integrate philosophy and values reflection further in their teaching/learning, a good starting point would be Molthan-Hill 2014b, Crane and Matten 2010 or Fisher et al. 2012. There are also some recommendations in the teaching aid that accompanies this book (details of how to acquire it are on page 4).

\section{Mission, strategy and key decision-makers}

Fundamentally our proposed new framework requires a clear commitment from the senior management of business schools, especially deans, in order to offer or even embed sustainability into the curriculum. This should start at university level. For example, Nottingham Trent University has since 2010 promoted graduate attributes in sustainability, which have been a key driver for change not only in the business school but throughout the university. Furthermore, a business school should preferably integrate sustainability into its mission and its strategy. Ryan and Tilbury (2013) have also shown how the quality assurance and quality enhancement system could support and promote sustainability teaching throughout courses and modules. The position of a sustainability coordinator could be created to work with course and module leaders on how to embed sustainability into their modules, as well as co-ordinating all such efforts so that students do not carry out the same case study over and over again. Finally, a study by the European Foundation of Management Development and the Academy of Business in Society, which interviewed 131 deans and 136 faculty respondents, suggests that key decision-makers, such as the head of undergraduate studies, can help (or hinder) the process if they provide leadership in shaping and implementing their institution's sustainability-related agenda and objectives (Morland-Painter et al. 2014). Engaged staff can add to existing modules 
or courses, as in the 'Piggyback' approach mentioned earlier. However, 'Mainstreaming' can be only achieved if key decision-makers support the integration of sustainability in all modules and courses. This book offers enough material to achieve that, and our proposed new framework as presented in Figure 2 will help the appropriate decisions to be made.

\section{Conclusion}

To summarise, our proposed new framework includes all the dimensions discussed above in addition to those suggested by Godemann et al. (2011):

- General sustainability knowledge, such as climate change

- Subject-specific knowledge, such as tools for sustainable marketing

- Specialised knowledge, such as environmental management systems

- Sustainability literacy skills, such as systems thinking instead of a myopic view

- Understanding of values underpinning management, so that the integration of values reflection forms the basis of management education

- Philosophical assumptions in business, which can be discussed with students or decided for them (optional), with in either case these underlying assumptions being made transparent for students

- Engagement with business, so that students solve 'real life' problems for business and society

- Strategic decision-making: mission, strategy, and quality assurance process all aligned and supported by key decision-makers.

When developing an approach for a business school/course/module, our proposed new framework enables the following core questions to be addressed:

- How will it be embedded? 
- What should be taught?

- Will it comprise subject-specific knowledge, general sustainability-related knowledge and/or sustainability literacy skills?

- Will the students solve 'real life' problems?

- Do the structures and strategies and key decision-makers support the decisions taken?

\section{Further reading}

Murray, P. (2011) The Sustainable Self: A Personal Approach to Sustainability Education (London: Earthscan).

This book contains numerous worksheets to build sustainability literacy or to facilitate learning about a particular aspect of sustainability.

Stibbe, A. (ed.) (2009) The Handbook of Sustainability Literacy: Skills for a Changing World (Totnes, UK: Green Books).

Thise book has been mentioned several times in this chapter and contains individual essays on topics such as carbon capability and systems thinking, which may be useful for general reading or as a base for learning activities. In particular, Zoe Robinson makes specific suggestions for business in 'Greening Business: The Ability to Drive Environmental and Sustainability Improvements in the Workplace' (pp. 130-36).

Weybrecht, Giselle (2013) The Sustainable MBA: A Business Guide to Sustainability, 2nd edn (Chichester: John Wiley \& Sons).

If you want to integrate more tools and concepts into your modules, you will find rich material in Weybrecht's book. It is also organised around the core subjects and offers tools in line with the MBA curriculum. The Sustainable MBA can be used to supplement our teaching material and ideas presented here; alternatively, some of our teaching ideas can be also adapted to the MBA and Master's curriculum in order to broaden the variety of the tools offered in The Sustainable MBA. 


\section{References}

Bird, F., and J. Waters (1989) 'The Moral Muteness of Managers', California Management Review 32.1: 73-88.

Bodenstein, G., A. Spiller and H. Elbers (1997) Strategische Konsumentscheidungen: Langfristige Weichenstellungen fuer das Umwelthandeln: Ergebnisse einer empirischen Studie, Diskussionsbeitraege des Fachbereichs Wirtschaftswissenschaften, 234 (Duisburg, Germany: Gerhard-Mercator-Universitaet).

Clayton, A.M.H., and N.J. Radcliffe (1996) Sustainability. A Systems Approach (London: Earthscan).

Courtice, P., and M. Van der Kamp (2013) Developing Leaders for the Future: Integrating Sustainability into Mainstream Leadership Programmes, working paper of the Cambridge Programme for Sustainability Leadership, commissioned by the Academy of Business in Society.

Crane, A., and D. Matten (2010) Business Ethics: Managing Corporate Citizenship and Sustainability in the Age of Globalization (Oxford, UK: Oxford University Press).

Fisher, C., A. Lovell and N. Valero-Silva (2012) Business Ethics and Values (Harlow, UK: Financial Times Prentice Hall).

Godemann, J., C. Herzig and J. Moon (2011) 'Approaches to Changing the Curriculum', paper presented at the ISIBS Workshop: Session II, University of Nottingham, UK, 20-21 October 2011.

Goworek, H., and P. Molthan-Hill (2013) 'Embedding CSR within the Undergraduate Business Curriculum: The Development of a Sustainable Organisation Module', in J. Ahmad and D. Crowther (eds), Education and Corporate Social Responsibility: International Perspectives (Bingley, UK: Emerald Publishing).

Habermas, J. (1984) The Theory of Communicative Action. Volume 1: Reason and the Rationalization of Society (London: Heinemann).

Jones, T.M. (1991) 'Ethical decision making by individuals in organizations: an issue-contingent model', Academy of Management Review 16: 366-95.

Kempton, W., J.S. Boster and J.A. Hartley (1996) Environmental Values in American Culture (Cambridge, MA: The MIT Press).

Kenrick, J. (2009) 'Commons Thinking: The Ability to Envisage and Enable a Viable Future through Connected Action', in A. Stibbe (ed.), The Handbook of Sustainability Literacy: Skills for a Changing World (Totnes, UK: Green Books): 51-57.

Lacy, P., T. Cooper, R. Hayward and L. Neuberger (2010) A New Era of Sustainability: UN Global Compact-Accenture CEO Study 2010, www.accenture.com/ SiteCollectionDocuments/PDF/Accenture_A_New_Era_of_Sustainability_ CEO_Study.pdf, accessed 31 March 2014.

MacIntyre, A. (1981) After Virtue: A Study in Moral Theory (London: Duckworth). 
McMurtry, J. (2012) 'Behind Global System Collapse: The Life-Blind Structure of Economic Rationality’, Journal of Business Ethics 108.1: 49-60.

Meadows, D.H. (2008) Thinking in Systems: A Primer (White River, VT: Chelsea Green).

Meadows, D.L. (2001) Fish Banks, Ltd: Game Administrator's Manual (Durham, NH: University of New Hampshire).

Molthan-Hill, P. (2014a) 'The Moral Muteness of Managers: An Anglo-American Phenomenon? German and British Managers and their Moral Reasoning about Environmental Sustainability in Business', International Journal of Cross Cultural Management, forthcoming.

— (2014b) 'Making the Business Case: Intercultural Differences in Framing Economic Rationality Related to Environmental Issues', Critical Perspectives on International Business, forthcoming.

Morland-Painter, M., E. Sabet, P. Molthan-Hill and H. Goworek (2014) ‘A Systemic Approach to Embedding Sustainability and Ethics into Management Education Globally: Is There Unity in Diversity?', paper to be presented at the EBEN conference, Berlin, Germany, 12-14 June 2014.

Murray, P. (2011) The Sustainable Self: A Personal Approach to Sustainability Education (London: Earthscan).

Robertson, M. (2014) Sustainability Principles and Practice (Oxon, UK: Routledge).

Robinson, Z. (2009) 'Greening Business: The Ability to Drive Environmental and Sustainability Improvements in the Workplace', in A. Stibbe (ed.), The Handbook of Sustainability Literacy: Skills for a Changing World (Totnes, UK: Green Books): 130-36.

Rusinko, C.A. (2010) 'Integrating Sustainability in Management and Business Education', The Academy of Management Learning and Education 9.3: 507-19.

Ryan, A., and D. Tilbury (2013) 'Uncharted Waters: Voyages for Education for Sustainable Development in the Higher Education Curriculum', The Curriculum Journal 24.2 (special issue: Education for Sustainable Development as the DESD Approaches 2014: What Have We Achieved and Ways Forward?): 2-13.

Schoemaker, P.J.H. (2008) 'The Future Challenges of Business: Rethinking Management Education', California Management Review 50.1: 119-39.

Sterling, S. (2009) 'Ecological Intelligence: Viewing the World Relationally', in A. Stibbe (ed.), The Handbook of Sustainability Literacy: Skills for a Changing World (Totnes, UK: Green Books): 77-83.

Stibbe, A. (ed.) (2009) The Handbook of Sustainability Literacy: Skills for a Changing World (Totnes, UK: Green Books).

Trapp, N.L. (2011) 'Staff Attitudes to Talking Openly About Ethical Dilemmas: The Role of Business Ethics Conceptions and Trust', Journal of Business Ethics 103.4: 543-52. 
Verhezen, P. (2010) 'Giving Voice in a Culture of Silence: From a Culture of Compliance to a Culture of Integrity', Journal of Business Ethics 96.2: 187-206.

Watson, M. (2009) 'Material Awareness: The Ability to Expose the Hidden Impact of Materials on Sustainability', in A. Stibbe (ed.), The Handbook of Sustainability Literacy: Skills for a Changing World (Totnes, UK: Green Books): 137-43. Watson, T.J. (2003) 'Ethical Choice in Managerial Work: The Scope for Moral Choices in an Ethically Irrational World', Human Relations 56: 167-85.

Weybrecht, Giselle (2013) The Sustainable MBA: A Business Guide to Sustainability, 2nd edn (Chichester: John Wiley \& Sons). 